actinium B was undoubtedly present. (New nomenclature after Rutherford and Geiger, Phil. Mag., 22 , p. $62 \mathrm{x}$, is used throughout this communication.)

Closer investigations of the conditions of this phenomenon established the fact that this removal of the active products from the anode took place only in the case when the activated plate serving as anode was used during a preceding electrolysis of water as kathode, or, in other words, was previously electrolytically saturated with hydrogen. This saturation of the plate with hydrogen was found as the necessary condition for making possible the removal of the radio-active products from the anode. The atoms of the active deposit were driven under the action of the great applied electromotive force as ions into the pure water. If the plate had been previously sufficiently saturated with hydrogen, and used then as anode, it was possible by applying a great P.D. to drive from it into the water in a few seconds a great part, viz. up to two-thirds, of the active products deposited on it. On the other hand, it was not possible to deprive the plate of its total activity even by applying a P.D. of 840 volts, nor by electrolysis during half an hour. The more detailed results of these investigations will be given elsewhere.

TADeusz GodlewsKi.

Lemberg, Physical Laboratory of the Technical

High School, March is.

\section{Autophanous Eyes.}

I HAVE been greatly interested by the correspondence lately appearing in NATURE on the subject of eyes gleaming in the dark, and there are one or two points about which I should much like to hear a little more.

With regard to human eyes never glowing, I knew one case some years ago of a young Scotch girl whose eyes glowed with a distinct deep-red light. She was a fair-complexioned girl with auburn hair and the peculiar red-brown eyes which go with that colouring.

On the subject of cats' eyes, can anyone tell me why the glow is invariably red in blue-eyed cats and green with yellow or green eyes, as the glow is not from the iris, but from the tapetum? I had a halfPersian cat for years with one blue and one yellow eye, and in the dark they were perfect little "port" and "starboard" lights. The red glow of the blueeyed cat, whether Persian or Siamese, is a deep ruby (not spinel like a mouse's eyes), and is noticeable even with tiny kittens before the colour of the iris is developed at all.

With Persian kittens it is possible to tell as soon as their eyes are open whether they will have blue or vellow eyes by placing them so that the glow can be seen, i.e. with a light in line with the observer's own eyes, those which will later develop a blue iris showing like rubies, and the future vellow or green iris like emeralds. Having at present six Siamese cats (fawn-coloured, with deep-blue eyes) and a Persian (black, with yellow eyes), I have considerable opportunities of observing them.

\section{Charlotte I. Wheflek Cuffe.}

Brachead, Kokine, Rangoon, March I.

THE phenomenon of "glowing" eyes (autophanous or not) is certainly observed in man. Without taking much interest in the matter, I have noticed three cases, one abroad and years ago, and the other two quite recently in London. In Room to of the L.C.C. Technical Institute, Dalston Lane, N.E., with all lights switched on, I observed the phenomenon over and over again by standing between the lecturer's table and the front bench and looking down at the student sitting in the middle (who should be looking up at you). I should add that I assumed the matter NO. 22 I3, VOL. 89 ] to be a function of the position after I had seen it in two students; before then I thought it was a peculiarity of the one student.

Sibpur College, Calcutta, March 7 .

\section{RAND GEOLOGY.}

$\mathrm{N}$ no other part of the world is the work of the geologist linked up with such varied interests as in the little strip-some fifty miles long - of high tableland in the Transvaal known as the Witwatersrand, on which are situated some sixty producing gold-mines with an annual output of 350 tons of fine gold, worth $35,000,000 l$.; and, indeed, in no other district has the geologist such opportunities for prosecuting his researches as are afforded by the innumerable prospecting trenches, shafts, and deep borings that have been put down on the Rand in the search of extensions, along the strike and on the dip, of the auriferous conglomerates. Hundreds of thousands of pounds have been spent on prospecting work of this nature. In one area alone near the Springs, in the East Rand, the writer of this review had the technical supervision of a series of deep borings, costing above 30,oool., and successfully located the eastern end of the Witwatersrand syncline, with its valuable gold-bearing seam there concealed beneath a thousand-foot cover of the later unconformable Dolomite formation.

The Transvaal Geological Survey, which, since its reconstruction after the war, has been working mainly in the northern part of the Transvaal, has at last broken ground on the Witwatersrand, and the report for Igro contains an important instalment of this work, in which Dr. Mellor ${ }^{2}$ summarises the results of his mapping of the lower Witwatersrand beds between Maraisburg and Rietfontein, an area including the municipality of Johannesburg and the Bezuidenhout valley, the geological structure of which presents so many points of interest. The main features of this area have long been known : they were sketched broadly by Walcot Gibson in a paper read before the Geological Society in 1892 ; and the boundary lines of the various subdivisions of the Witwatersrand beds were mapped by Messrs. Hatch and Corstorphine, and published in the Transactions of the Geological Society for South Africa for 1904.

Dr. Mellor's mapping of these subdivisions agrees in the main with that of his predecessors; but he explains the duplication of the lower Witwatersrand beds by a new reading of the faulting, which on his view took place subsequently to the extrusion of the Klipriversburg amygdaloid. His map also records a hitherto unnoticed strip of sheared granite on the farm Rietfontein No. I45, that throws fresh light on the age of the movements responsible for the dislocations. The publication of the further work of the Survey on the Rand, especially at its extreme eastern and western ends, will be awaited with interest.

\section{F. H. H.}

1 Report of the Geological Survey for rgro, Union of South Africa Mines Department, Pretoria, 19ri. Pp. I13, with 9 plates and 5 maps Price $7 s .6 d$

Portion of the Central Witwatersrand." By E. T. Mellor. Pp. $22-38$ of the Report. 